\title{
Orthogonal Protein Interactions in Spore Pigment Producing and Antibiotic Producing Polyketide Synthases
}

\author{
Taek Soon Lee, Chaitan Khosla, Yi Tang
}

Received: August 19, 2005 / Accepted: September 26, 2005

(C) Japan Antibiotics Research Association

\begin{abstract}
The actinomycetes produce antibiotics as well as spore pigments during their life cycle by using Type II polyketide synthases (PKSs). Each PKS minimally consists of a ketosynthase heterodimer and an acyl carrier protein. The acyl carrier protein has been shown to be interchangeable among different antibiotic producing Type II PKSs. Surprisingly, we have discovered a fundamental incompatibility between the ketosynthases and acyl carrier proteins from antibiotic producing pathways and those from spore pigment pathways. Although antibiotic PKSs can interact with acyl carrier proteins from spore pigment pathways, spore pigment PKSs are unable to recognize acyl carrier proteins from polyketide antibiotic pathways. This observation provides an insight into a critical mechanism by which natural product biosynthetic specificity is exercised by members of this bacterial family.
\end{abstract}

Keywords polyketide synthase, ketosynthase, acyl carrier protein, spore pigment, antibiotic

The actinomycetes, which include the genus Streptomyces, are soil bacteria that are well known for their exceptional ability to produce biologically active compounds [1]. Thousands of antibiotics have been identified from these microorganisms, which are frequently isolated as colored spores from soil samples [2]. The antibiotics and the spore pigments of the actinomycetes are biosynthesized as secondary metabolites by polyketide synthases (PKSs). Although the genes encoding numerous antibiotic producing PKSs have been studied to date [3 5], only a few spore pigment producing PKSs, including whiE gene cluster of Streptomyces coelicolor, have been analyzed [6 9]. In part, this difference is due to the difficulty of isolating and characterizing spore pigments, which are presumably covalently attached to macromolecular components of spores [10].

Although the precise structures of most spore pigments are unknown, their biosynthesis is catalyzed by type II PKSs, analogous to the biosynthesis of polyfunctional aromatic polyketides such as actinorhodin, tetracycline and daunorubicin. By expressing subsets of various spore pigment biosynthetic genes and characterizing the resultant products, Moore et al. were able to identify some of the salient structural features of spore pigments from $S$. coelicolor as well as S. halstedii [11] (Fig. 1). In turn, these findings yielded a range of new polyketides via combinatorial biosynthesis [11].

By analyzing mutant strains of $S$. coelicolor, which produces both actinorhodin and the whiE spore pigment, it has been suggested that the polyketide synthase components from antibiotic pathways and spore pigment pathways are interchangeable [7,12]. Based on this observation, we attempted to engineer an alkylacyl-primed analog of aklanonic acid by co-expressing the $\mathrm{C}_{24}$ sch or whiE spore pigment PKSs and the genes encoding the R1128 initiation PKS module [13]. Unexpectedly, no products corresponding to a productive interaction between
C. Khosla (Corresponding author): Departments of Chemistry, Chemical Engineering, and Biochemistry, Stanford University, Stanford, California 94305, U.S.A. E-mail: khosla@stanford.edu
T. S. Lee: Department of Chemistry, Stanford University, Stanford, California 94305, U.S.A.

Y. Tang: Department of Chemical Engineering, University of California at Los Angeles, Los Angeles, California, 90095, U.S.A. 


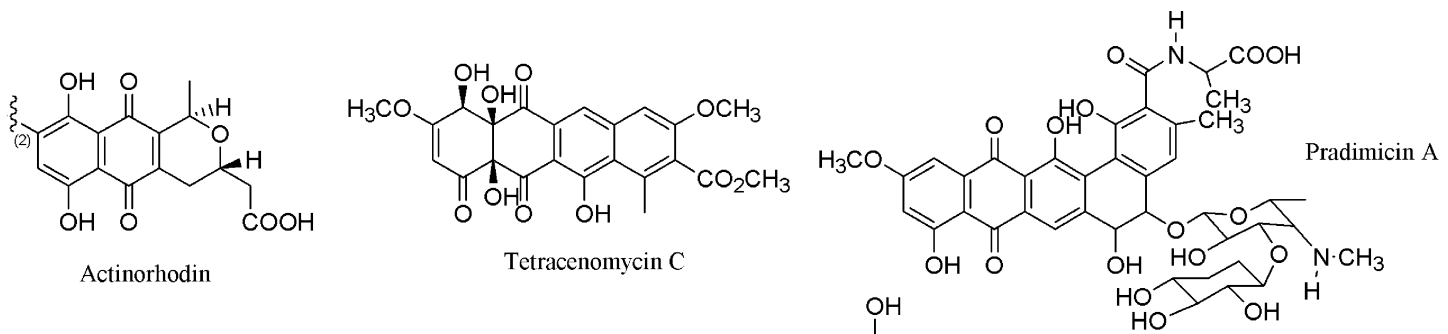<smiles>CC1(O)CC(=O)c2c(Cc3cc(O)cc(=O)o3)cc(O)cc2O1</smiles><smiles>Cc1cc(O)cc2c1C(=O)CC(O)(Cc1cc(O)cc(=O)o1)O2</smiles><smiles>Cc1cc(O)c(C(=O)c2c(O)cc(O)cc2Cc2cc(O)cc(=O)o2)c(O)c1</smiles><smiles>Cc1cc(O)c2c(c1-c1cc(O)cc(=O)o1)C(=O)c1cc(O)cc(O)c1C2=O</smiles><smiles>Cc1c(C(=O)c2c(O)cc(O)cc2Cc2cc(O)cc(=O)o2)c(O)cc2c1C(=O)C(O)=CC2=O</smiles><smiles>CC(=O)CC1=Cc2cccc3c(C(=O)c4c(C)cc(O)cc4O)c(O)cc(c23)O1</smiles><smiles>Cc1cc(O)cc(O)c1C(=O)c1c(Cc2cc(O)cc(=O)o2)cc2cc(O)cc(O)c2c1O</smiles>

Fig. 1 Aromatic polyketides.

Actinorhodin, tetracenomycin C, and pradimicin A are antibiotics biosynthesized by natural polyketide synthases. SEK-compounds and TW-compounds are engineered polyketides biosynthesized from reconstituted antibiotic and spore pigments producing PKSs, respectively.

the R1128 initiation module and either spore pigment elongation module were observed. In contrast, when an equivalent $\mathrm{C}_{24}$ ketosynthase heterodimer from the pradimicin $(p m s)$ PKS was recombined with the R1128 initiation module, the engineered host was able to afford the expected products of the bimodular PKS. This observation suggested that there may be a fundamental incompatibility between PKS components from antibiotic and spore pigment pathways. Here, we test this hypothesis via a series of in vitro assays utilizing purified PKS proteins from different antibiotic and spore pigment pathways.

Although previous studies had shown that acyl carrier proteins (ACPs) from antibiotic biosynthetic pathways could be interchanged in vivo [14] and in vitro [15] without significant kinetic penalties, we speculated that the observed lack of crosstalk between heterologous spore pigment and antibiotic PKS subunits was primarily due to their inability to engage in catalytically productive proteinprotein interactions. To test this hypothesis, we first investigated the properties of the ketosynthase-chain length factor (KS-CLF) heterodimer and ACP from the sch PKS, a representative dodecaketide synthase involved in spore pigment biosynthesis [8]. Purified sch KS-CLF was titrated in vitro with various ACPs (Fren $\mathrm{N}$ from frenolicin PKS, Zhu N from R1128 PKS, GraACP from granaticin PKS,
WhiE ACP from whiE PKS, and Pms ACP from pradimicin PKS) $[11,15,16]$. Assays were performed at $30^{\circ} \mathrm{C}$ in $10 \mu \mathrm{l}$ of reaction buffer containing $10 \%$ glycerol as previously described [15]. With $2 \mu \mathrm{M}$ of the KS-CLF heterodimer, 0.5 $\mu \mathrm{M}$ malonyl-CoA : ACP transacylase (MAT), and $30 \mu \mathrm{M}$ of different holo-ACPs in each reaction, the reaction was initiated by adding $2 \mathrm{mM}{ }^{14} \mathrm{C}$-malonyl-CoA and quenched by adding $10 \mu \mathrm{l} 12.5 \%$ SDS after 30 minutes. For comparison, act and tcm KS-CLFs were also assayed along with sch KS-CLF. Each quenched mixture was extracted with ethyl acetate and analyzed by thin-layer chromatography (TLC). The amount of product accumulated at the end of the reaction is shown in Fig. 2, and the kinetic parameters associated with each biosynthetic reaction are reported in Table 1. The identity of the product of each reaction mixture was verified by comparison with authentic standards of SEK4/4b, SEK15/15b, and TW93c/93d isolated from appropriate recombinant cell lines $[11,13,17]$ (Fig. 1).

Our data revealed that the sch KS-CLF could synthesize polyketide in conjunction with the WhiE ACP but not any other heterologous ACP from antibiotic biosynthetic pathways, including the fren, gra, dps, and R1128 PKSs (Fig. 2). The absolute rate of dodecaketide synthesis in vitro by the sch KS-CLF outfitted with the WhiE ACP was 
Table 1 Activities of various KS-CLFs toward ACPS

\begin{tabular}{|c|c|c|c|c|c|c|}
\hline & & FrenN & ZhuN & Gra ACP & WhiE ACP & Pms ACP \\
\hline \multirow[t]{4}{*}{ act KS-CLF } & $\mathrm{K}_{\mathrm{m}}(\mu \mathrm{M})$ & $5.8 \pm 0.4$ & $2.7 \pm 0.2$ & $6.4 \pm 1.5$ & $3.8 \pm 2.1$ & $3.7 \pm 0.2$ \\
\hline & $\mathrm{k}_{\text {cat }}\left(\min ^{-1}\right)$ & $0.27 \pm 0.005$ & $0.18 \pm 0.002$ & $0.17 \pm 0.01$ & $0.13 \pm 0.02$ & $0.11 \pm 0.02$ \\
\hline & $\mathrm{k}_{\mathrm{cat}} / \mathrm{K}_{\mathrm{m}}\left(\mathrm{min}^{-1} \mathrm{mM}^{-1}\right)$ & 47 & 66 & 27 & 34 & 31 \\
\hline & $\mathrm{k}_{\mathrm{rel}}$ & 1 & 1.40 & 0.57 & 0.72 & 0.66 \\
\hline \multirow[t]{4}{*}{ tcm KS-CLF } & $\mathrm{K}_{\mathrm{m}}(\mu \mathrm{M})$ & $2.3 \pm 0.3$ & $1.4 \pm 0.2$ & $1.6 \pm 0.3$ & $3.0 \pm 1.2$ & $2.8 \pm 0.6$ \\
\hline & $\mathrm{k}_{\text {cat }}\left(\min ^{-1}\right)$ & $0.32 \pm 0.01$ & $0.31 \pm 0.01$ & $0.36 \pm 0.01$ & $0.13 \pm 0.01$ & $0.15 \pm 0.08$ \\
\hline & $\mathrm{k}_{\mathrm{cat}} / \mathrm{K}_{\mathrm{m}}\left(\mathrm{min}^{-1} \mathrm{mM}^{-1}\right)$ & 139 & 219 & 225 & 43 & 56 \\
\hline & $\mathrm{k}_{\text {rel }}$ & 1 & 1.58 & 1.62 & 0.31 & 0.40 \\
\hline \multirow[t]{3}{*}{ sch KS-CLF } & $\mathrm{K}_{\mathrm{m}}(\mu \mathrm{M})$ & & & & $2.1 \pm 1.2$ & \\
\hline & $k_{\text {cat }}\left(\min ^{-1}\right)$ & No Activity & No Activity & No Activity & $0.37 \pm 0.06$ & No Activity \\
\hline & $\mathrm{k}_{\text {cat }} / \mathrm{K}_{\mathrm{m}}\left(\mathrm{min}^{-1} \mathrm{mM}^{-1}\right)$ & & & & 176 & \\
\hline \multirow[t]{4}{*}{ pms KS-CLF } & $\mathrm{K}_{\mathrm{m}}(\mu \mathrm{M})$ & $1.6 \pm 0.5$ & $1.7 \pm 0.6$ & $2.8 \pm 0.6$ & $2.3 \pm 0.7$ & $2.7 \pm 0.4$ \\
\hline & $\mathrm{k}_{\text {cat }}\left(\min ^{-1}\right)$ & $0.20 \pm 0.01$ & $0.28 \pm 0.02$ & $0.95 \pm 0.05$ & $0.61 \pm 0.04$ & $0.28 \pm 0.01$ \\
\hline & $\mathrm{k}_{\text {cat }} / \mathrm{K}_{\mathrm{m}}\left(\mathrm{min}^{-1} \mathrm{mM}^{-1}\right)$ & 126 & 163 & 340 & 266 & 106 \\
\hline & $\mathrm{k}_{\mathrm{rel}}$ & 1 & 1.29 & 2.70 & 2.11 & 0.84 \\
\hline
\end{tabular}

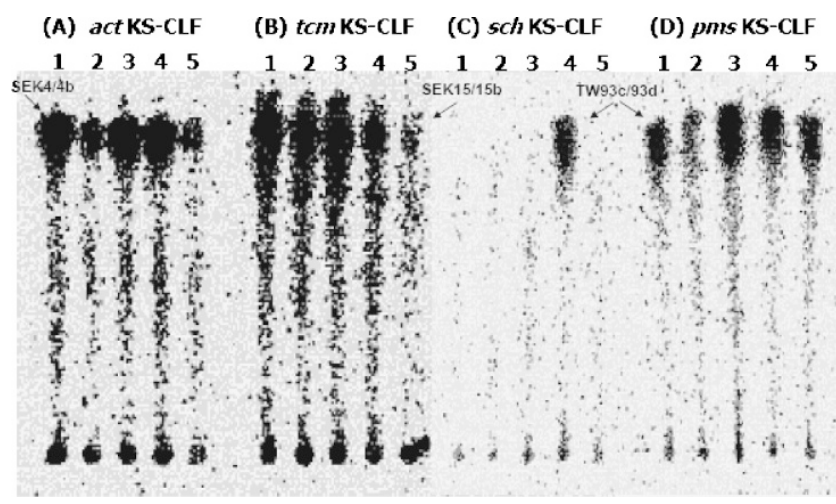

Fig. 2 Polyketide biosynthesis in vitro with heterologous combinations of ACP and KS-CLF from various antibiotic and spore pigment polyketide synthases (PKSs).

Radiolabeled polyketides synthesized by the minimal PKS from ${ }^{14} \mathrm{C}$-malonyl-CoA are detected by thin layer chromatography, followed by phosphorimager counting. (A) act KS-CLF, (B) tcm KSCLF, (C) sch KS-CLF, (D) pms KS-CLF. Five different ACPs were used, including (FrenN(1), ZhuN(2), Gra ACP(3), WhiE ACP(4), Pms $A C P(5))$ are used. Different solvent conditions were used for similar Rf of polyketide products. For experimental details, see text.

comparable to the rate of octaketide and decaketide synthesis by the act and tcm KS-CLF, respectively (Table 1). Thus, it appears that spore pigment KS-CLF heterodimers have exceptionally high specificity for ACPs from spore pigment pathways. In contrast, the act and $t c m$ KS-CLFs were able to interact with the WhiE ACP fruitfully, producing the expected octaketides (SEK4 and
SEK4b) and decaketides (SEK15 and SEK15b), respectively. Since the rate of malonylation of holo-ACP by MAT is much faster than that of condensation of the malonyl-ACP by KS/CLF [15], the MAT catalyzed reaction is unlikely to be the bottleneck in the above assay.

To rule out the possibility that chain length differences are responsible for the above observations, we extended these findings by assaying purified pms KS-CLF. The pms KS-CLF was cloned from Actinomadura hibisca [16], expressed in S. coelicolor and purified as described for the tcm KS-CLF [14] to $>80 \%$ homogeneity. Consistent with in vivo observations [13], the purified pms KS-CLF synthesized the expected dodecaketides at wild-type or near wild-type rates in the presence of either heterologous antibiotic or spore pigment ACPs (Table 1).

At first glance our findings may appear somewhat contradictory with in vivo results of Yu and Hopwood [7]. These investigators reported that, not only could the whiE ACP gene complement a lesion in the act ACP gene to yield actinorhodin, but the act ACP gene could also partially complement a mutant whiE ACP gene to induce pale grey pigmentation of spores. The precise reasons for this difference are unclear. Perhaps it reflects a somewhat relaxed ACP specificity of the whiE KS-CLF as compared to the sch KS-CLF. This is unlikely because experiments in our own laboratory involving co-expression of genes encoding the whiE KS-CLF and either ACP from the R1128 PKS yielded no polyketide product (unpublished results). Alternatively, Yu and Hopwood's observation may not reflect true complementation, rather the spores may 
have appeared pale grey due to diffusion of a small amount of actinorhodin from the substrate mycelium into spores. (A similar pale grey color was also observed when the act KS-CLF was used to complement a mutant whiE KS-CLF.) Further work will be required to understand the apparent partial complementation of the whiE spore pigment pathway in vivo by the act ACP.

In conclusion, we have uncovered a fundamental incompatibility at the level of protein-protein interactions between antibiotic producing PKSs and spore pigment producing PKSs. This finding may contribute to understand the biochemical logic of PKS specificity during contemporaneous antibiotic and spore pigment synthesis in the life cycle of an actinomycete bacterium. It could also pave the way to engineer new types of "hybrid" polyketides by rationally combining spore pigment and antibiotic biosynthetic pathways.

Acknowledgments We thank David Hopwood (John Innes Centre, Norwich, United Kingdom) for helpful discussions. This work was supported by a grant from the National Institutes of Health (NIH) (CA 77248 to CK).

\section{References}

1. Hodgson DA. Primary metabolism and its control in Streptomycetes: a most unusual group of bacteria. Adv Microb Physiol 42: 47-238 (2000)

2. Miyadoh S, Hamada M, Hotta K, Kudo T, Seino A, Vobis G, Yokota A. Atlas of Actinomycetes. Asakura Publishing Co., Tokyo (1997)

3. Hutchinson CR, Fujii I. Polyketide synthase gene manipulation: a structure-function approach in engineering novel antibiotics. Annu Rev Microbiol 49: 201-238 (1995)

4. Lal R, Khanna R, Kaur H, Khanna M, Dhingra N, Lal S, Gartemann KH, Eichenlaub R, Ghosh PK. Engineering antibiotic producers to overcome the limitations of classical strain improvement programs. Crit Rev Microbiol 22: 201255 (1996)

5. Dairi T. Studies on biosynthetic genes and enzymes of isoprenoids produced by actinomycetes. J Antibiot 58: 227243 (2005)

6. Davis NK, Chater KF. Spore colour in Streptomyces coelicolor A3(2) involves the developmentally regulated synthesis of a compound biosynthetically related to polyketide antibiotics. Mol Microbiol 4: 1679-1691 (1990)

7. Yu TW, Hopwood DA. Ectopic expression of the Streptomyces coelicolor whiE genes for polyketide spore pigment synthesis and their interaction with the act genes for actinorhodin biosynthesis. Microbiology 141: 2779-2791 (1995)

8. Blanco G, Pereda A, Mendez C, Salas JA. Cloning and disruption of a fragment of Streptomyces halstedii DNA involved in the biosynthesis of a spore pigment. Gene 112: 59-65 (1992)

9. Bergh S, Uhlen M. Analysis of a polyketide synthesisencoding gene cluster of Streptomyces curacoi. Gene 117: 131-136 (1992)

10. Brian P. A Developmentally Regulated Spore Pigment Locus from Streptomyces coelicolor A3(2). University of East Anglia, Norwich, UK (1992)

11. Yu TW, Shen Y, McDaniel R, Floss HG, Khosla C, Hopwood DA, Moore BS. Engineered biosynthesis of novel polyketides from Streptomyces spore pigment polyketide synthases. J Am Chem Soc 120: 7749-7759 (1998)

12. Kim ES, Hopwood DA, Sherman DH. Analysis of type II polyketide beta-ketoacyl synthase specificity in Streptomyces coelicolor A3(2) by trans complementation of actinorhodin synthase mutants. J Bacteriol 176: 1801-1804 (1994)

13. Lee TS, Khosla C, Tang Y. Engineered biosynthesis of aklanonic acid analogs. J Am Chem Soc 127: 12254-12262 (2005)

14. Khosla C, McDaniel R, Ebert-Khosla S, Torres R, Sherman DH, Bibb MJ, Hopwood DA. Genetic construction and functional analysis of hybrid polyketide synthases containing heterologous acyl carrier proteins. J Bacteriol 175: 2197-2204 (1993)

15. Tang Y, Lee TS, Kobayashi S, Khosla C. Ketosynthases in the initiation and elongation modules of aromatic polyketide synthases have orthogonal acyl carrier protein specificity. Biochemistry 42: 6588-6595 (2003)

16. Dairi T, Hamano Y, Igarashi Y, Furumai T, Oki T. Cloning and nucleotide sequence of the putative polyketide synthase genes for pradimicin biosynthesis from Actinomadura hibisca. Biosci Biotechnol Biochem 61: 1445-1453 (1997)

17. McDaniel R, Ebert-Khosla S, Fu H, Hopwood DA, Khosla C. Engineered biosynthesis of novel polyketides: influence of a downstream enzyme on the catalytic specificity of a minimal aromatic polyketide synthase. Proc Natl Acad Sci USA 91: 11542-11546 (1994) 